\title{
A INDÚSTRIA CULTURAL E A SOCIEDADE: um rompimento com a ordem estética através dos movimentos artísticos
}

\author{
PECAIBES, Viviane. Mestranda em Design, UNISINOS/RS \\ vivianepecaibes@gmail.com
}

\begin{abstract}
Resumo: Este artigo procura discutir como a sociedade contemporânea conseguiu contrapor a pressão imposta pela indústria cultural, através dos movimentos artísticos, como a Pop Art e a Art Kitsch, de acordo com o ponto de vista de autores que apresentam fundamentos para a pesquisa sobre esses movimentos importantes da história e do design.
\end{abstract}

Palavras-chave: indústria cultural, estética, expressão, pop art, art kitsch.

\begin{abstract}
This article discusses how contemporary society has managed to oppose the pressure imposed by the culture industry, through the artistic movements as Pop Art and Kitsch Art, according to the view of the authors who show fundamentals for research on these important movements history and design.
\end{abstract}

Keywords: cultural industries, aesthetics, expression, pop art, art kitsch.

\section{INTRODUÇÃO}

O conceito indústria cultural foi criado pelos filósofos e sociólogos alemães Theodor Adorno e Max Horkheimer, a fim de designar a situação da arte na sociedade capitalista industrial. Para eles, o gosto e a atitudes que anunciam a nossa identidade, são articulados e ditados pelas classes dominantes para o favorecimento do consumo (ADORNO, 1985).

A arte, durante essa "ditadura massificadora" perdeu o seu poder contestatório e erudito, porque para a indústria cultural, uma sociedade plenamente culta e arejada é difícil de ser domesticada. As pessoas sofriam uma violência simbólica por parte da indústria cultural. Este conceito elaborado por Pierre Bourdieu é uma forma de coerção que se baseia no reconhecimento de uma imposição determinada, seja esta econômica, social ou simbólica. A violência simbólica se funda na criação de crenças no processo de socialização, que induzem o indivíduo a se posicionar no espaço social seguindo critérios e padrões do discurso dominante (BOURDIEU, 2001).

Esses padrões estéticos imperantes moldaram a sociedade como um todo, porém algumas pessoas encontraram nas expressões artísticas uma forma de combater esse poderio. A Contracultura foi a manifestação artística de atitude mais 
radical, na tentativa de quebra dos vínculos com a indústria cultural de massa (GOFFMAN, 2007).

A força deste movimento perdurou e fomentou outros movimentos artísticos, que no caso deste artigo, são destacados dois movimentos que possuem uma ligação estreita com o design, são eles: a Pop Art e a Art Kitsch.

Dessa forma, este artigo pretende discutir como a sociedade conseguiu contrapor a pressão imposta pela indústria cultural, através dos movimentos artísticos, como a Pop Art e a Kitsch Art.

\section{INDUSTRIAL CULTURAL}

A indústria cultural pode se considerada como o conjunto de articulações, que formam um sistema que visa principalmente à geração de lucros, exerce um tipo de manipulação e controle social porque está acessível às massas, ou seja, ela não só institui a mercantilização da cultura, como também assume um poder decisório quanto à visão estética, moral, postura e gosto da sociedade.

Segundo Adorno (1985), a técnica da indústria cultural levou à padronização e à produção em série, sacrificando o que fazia diferença entre lógica da obra e do sistema social. O fornecimento ao público de uma hierarquia de qualidades serve apenas para uma quantificação, onde a sociedade de massa é reduzida a um simples material estatístico para a produção de produtos para o seu tipo. Inevitavelmente, cada manifestação da indústria cultural reproduz as pessoas tais como as modelou a indústria em seu todo. Dessa forma, a sociedade sofreu uma espécie de "esquematismo", que separa as pessoas por padrões, onde o consumidor não possui mais a capacidade de classificar o que não tenha sido antecipado pela indústria cultural.

Esse mecanismo possui um poder social muito eficaz e, segundo Adorno, tolhe a preferência da massa e instaura o poder da técnica sobre o homem, criando condições favoráveis para a implantação de seu comércio.

Uma das formas de manifestação desse poder é com relação à diversão, para Adorno (1985):

A diversão é o prolongamento do trabalho sob o capitalismo tardio. Ela é procurada por quem quer escapar ao processo do trabalho mecanizado, para se pôr de novo em condições de enfrentá-lo. Mas, ao mesmo tempo, a mecanização atingiu tal poderio sobre a pessoa em seu lazer e sobre a sua felicidade, ela determina tão profundamente a fabricação das mercadorias destinadas à diversão, que esta pessoa não pode mais perceber outra coisa senão as cópias que reproduzem o próprio processo de trabalho. (pg. 128)

Assim, a indústria cultural dispõe produtos para nos tornamos consumidores ávidos pelo comercio da diversão, moldando o pensamento da sociedade com uma verdade antiga, de que a condição de vida é o desgaste contínuo, o esmagamento de toda resistência individual.

Mas esse poder exercido pela indústria cultural apesar de se mostrar eficaz, possui uma postura "aparentemente" democrática e liberal, a cultura massificada realiza impiedosamente os ditames de um sistema de dominação econômica que necessita de uma concordância das pessoas para a legitimação de sua existência. Porém a indústria cultural só se interessa pelos homens como clientes e empregados, 
e também, determina que a felicidade não deva chegar a todos, mas para quem é designado por uma potência superior. Os "felizardos" que são exibidos para a massa são exemplares que pertencem ao mesmo gênero do público, porém essa semelhança é a imposição de uma diferença absoluta, nesse sentido, Adorno (1985) afirma que:

Cada um é tão somente aquilo mediante o que pode substituir todos os outros: ele é fungível, um mero exemplar. Ele próprio, enquanto indivíduo é o absolutamente substituível, o puro nada, e é isso mesmo que ele vem perceber quando perde com o tempo a semelhança. É assim que se modifica a estrutura interna da religião do sucesso, à qual, aliás, as pessoas permanecem tão rigidamente agarradas. (pg. 136)

Essa manipulação social, por parte da indústria cultural, transforma e domina o gosto das pessoas também através da publicidade, que usufrui da beleza como acessório. Tornando o belo em útil. Dessa forma, a publicidade converte-se na arte pura e simplesmente se torna uma verdadeira representação do poderio social, invadindo o estilo e criando um novo idioma: o padrão inatingível, que todas as pessoas querem alcançar e que fomenta o consumo por status.

A publicidade quer mais do que estimular a compra: entrega-se ao mercado, como sedução, aonde os produtos irão, pela posse, diferenciar os atores sociais, definindo seu status. Nessa sociedade de consumo, as coisas não são possuídas por si mesmas, mas pelo que dizem, por sua potência comunicativa através da linguagem. Possuímos e compramos etiquetas que nada mais são do que figurações e enunciados especiais dos objetos: uma camada suplementar de significado, que está além de seu valor de uso, enquanto bem produzido. Os bens são símbolos e os símbolos, bens. (ADORNO, 1985)

De certa forma o inimigo que se combate na indústria cultural, é o inimigo que já está derrotado, o sujeito pensante. Todos podem ser como a sociedade poderosa, todos podem se tornar felizes, desde que se entreguem de corpo e alma, desde que renunciem à pretensão de felicidade pura e real. (ADORNO, 1985)

Esse poderio que a indústria cultural exerce sobre a sociedade, é uma espécie de violência velada que molda as necessidades e gosto das pessoas. Assim, a sociedade se comporta como refém, em um jogo de força, onde as pessoas se relacionam através signos e símbolos que podem os tornar dominantes ou dominados.

\section{VIOLÊNCIA SIMBÓLICA}

O conceito de Violência Simbólica, desenvolvido por Pierre Bourdieu, traz a compreensão das relações de dominação ocorridas entre as pessoas e entre os grupos presentes na sociedade, na qual corresponde a um tipo de violência que é exercida em parte com o consentimento de quem a sofre.

A violência simbólica é uma espécie de coerção instituída por intermédio da adesão que o dominado não pode deixar de conceder ao dominante (portanto, à dominação), quando dispõe apenas, para pensar sua relação com ele, de instrumentos de conhecimento partilhados entre si e que fazem surgir essa relação como natural, pelo fato de serem, na verdade, a forma incorporada da estrutura da relação de dominação. (BOURDIEU, 2001).

Segundo Bourdieu, em seu livro o Poder Simbólico (1998):

As diferentes classes estão envolvidas numa luta propriamente simbólica para imporem a definição de mundo social conforme 
seus interesses, e imporem o campo das tomadas de posições ideológicas reproduzindo as estratégias que tendem a reforçar dentro da classe e fora da classe a crença na legitimidade da dominação da classe. Elas podem conduzir essa luta diretamente, nos conflitos simbólicos da vida quotidiana, para poder impor instrumentos de conhecimento e de expressão arbitrários da realidade social. (Pg. 11 e 12)

Essa violência está presente nos símbolos e signos culturais, principalmente no reconhecimento da autoridade exercida por certas pessoas ou grupos de pessoas. Assim, a violência simbólica não é percebida como violência, mas como uma espécie de veto desenvolvido em um respeito que "naturalmente" se exerce sobre outro. Os dominados, de forma inconsciente e involuntária, absorvem para si os valores e a visão do mundo dos dominantes moldando-se como "réplicas" de um gosto que não é o seu para simular um estilo de vida que não condiz com a sua realidade.

Essa relação de poder exercida pelas classes sociais possui interesses próprios como é afirmada por Bourdieu (1998):

A cultura dominante contribui para a integração social da classe dominante (assegurando uma comunicação imediata entre todos os seus membros e distinguindo-os das outras classes); para a integração fictícia da sociedade no seu conjunto, portanto à desmobilização (falsa consciência) das classes dominadas; para a legitimação da ordem estabelecida por meio do estabelecimento das distinções (hierarquias) e para a legitimação dessas distinções. (Pg. 10)

Dessa forma, a dominação articulada, se tornou uma parte integrante e essencial na construção do gosto, moral e atitudes da sociedade, formando uma espécie de "coluna vertebral" da estética social. Impondo padrões estéticos que visavam a exposição das divisões das classes sociais, no intuito de criar uma segregação da sociedade, facilitando ainda mais seu domínio.

\section{PADRÕES ESTÉTICOS IMPOSTOS}

A noção de beleza não é única em todas as épocas da história e muito menos uniforme em todos os lugares. Os padrões de beleza da sociedade se modificam de acordo com o tempo e a cultura. O autor Umberto Eco, em seu livro Historia da Beleza (2004), observa essas mudanças, trazidas principalmente pela arte.

No decorrer da história buscou-se um modelo para a compreensão do belo e do feio, principalmente no mundo ocidental (ECO, 2004). Uma primeira percepção entre os dois conceitos é a relação de oposição. Enquanto a noção de beleza está associada a um prazer estético pelo gosto, a noção de feio seria o oposto, portanto, o desprazer, a repulsa, o incômodo.

O prazer estético relacionado ao belo traz consigo o prazer da fruição, associado à harmonia, equilíbrio, mas principalmente determinado por aquilo que um grupo social, culturalmente, identifica como belo (COSTA, 2004). O conceito de beleza é um valor estético que pode direcionar o gosto, a moral e postura da sociedade como um todo. Os valores estéticos possuem uma relação com a verdade dos sentidos e reconcilia, na realidade da liberdade, as faculdades da sensualidade e do intelecto do homem (MARCUSE, 1999).

Com o desenvolvimento da indústria cultural, foi decretada a associação da beleza com o consumo (COSTA, 2004). E principalmente, com a ação da publicidade, a 
beleza foi utilizada como mercadoria. Segundo Adorno (1985), a indústria cultural mecanizou a beleza para fomentar o comércio e distanciar as pessoas do valor estético original do belo que está relacionado à verdade dos sentidos:

A reprodução mecânica do belo - à qual serve a fortiori, com sua idolatria metódica de individualidade, a exaltação reacionária da cultura - não deixa mais nenhuma margem para a idolatria inconsciente a que se ligava o belo. As estrelas mais bem pagas assemelham-se a reclames publicitários para artigos de marca não especificada. Não é a toa que são escolhidas muitas vezes entre modelos comerciais. $O$ gosto dominante toma seu ideal na publicidade, da beleza utilitária. (Pg. 131 e 146)

O autor Umberto Eco (2004), complementa a visão de Adorno quanto a criação de uma nova beleza mercadológica:

A nova beleza é reprodutível, mas também é transitória e perecível: deve induzir o consumidor à substituição rápida, por consumpção ou desinteresse, para não deter o crescimento exponencial do circuito da produção, distribuição e consumo de mercadorias. (Pg. 377)

Nessa sociedade onde o consumo é feroz, regulador e ofensivo, algumas pessoas começaram a se sentir pressionadas e postam-se contra essa cultura dominadora. Não se colocam apenas contra os valores, mas também aos estilos de vida, as visões de mundo do poder e principalmente, contra a cultura intelectual dominante (CANEVACCI, 2005).

Utilizando expressões criativas como a arte e a música, essas pessoas se fizeram ouvir e marcaram a história com suas performances em um movimento artístico chamado Contracultura.

\section{CONTRACULTURA}

A contracultura surgiu, primeiramente, da crise e da doença da cultura estabelecida, e propôs a superação do preconceito de que, o que está instaurado e corrente é melhor do que o novo, que está surgindo ou está marginalizado em relação à cultura oficial imposta. Teve início nos anos 1950, porém seu auge foi no final da década de 1960 (GOFFMAN, 2007).

O autor Canevacci (2005) apresenta as principais características desse movimento artístico:

O prefixo "contra" atestava a dimensão da oposição que as novas culturas juvenis dirigiam à cultura dominante e hegemônica. Dentro do conceito de contracultura transita-se, portanto, de uma oposição radical contra alguma coisa dominante, em relação a propostas criativas, para algo totalmente distinto. Contra a cultura do poder e para as culturas de revolta, para a transformação do mundo, para acender um processo revolucionário nem tanto na estrutura socioeconômica, mas, sobretudo, no cruzamento das novas formas de pensar e velhas ideologias. (Pgs. 13 e 14)

Esse movimento produziu uma transformação radical da consciência, valores e comportamento que despertou a juventude do torpor moral em que vivia. Foi uma forma de contestação radical, porque quebrava com praticamente todos os hábitos 
consagrados de pensamentos e comportamentos da cultura dominante (GOFFMAN, 2007).

O discurso crítico que esse movimento elaborou ao longo dos anos 60 e 70 visava não apenas as contradições da sociedade capitalista, mas também aquelas da sociedade industrial, nas suas manifestações mais simples e corriqueiras. Neste período a contracultura teve seu lugar de importância, não apenas pelo poder de mobilização, mas principalmente, pela natureza de idéias que colocou em circulação, pelo modo como as veiculou e pelo espaço de intervenção crítica que abriu (GOFFMAN, 2007).

Os ideais revolucionários da contracultura, estenderam-se e fomentaram outras manifestações artísticas. Neste artigo, serão destacados dois movimentos que criaram uma nova linguagem para os objetos comuns, transformando-os em obras de arte e crítica para chamar a atenção das pessoas sobre as qualidades da verdadeira beleza, gerando um rompimento com a ordem estética estabelecida. Suas influencias se estendem até hoje na cultura e também, no design, são os movimentos: Pop Art e Art Kitsch.

\subsection{Pop Art}

Esse movimento de arte mais identificado com signos, consumismo e comunicação de massa, se desenvolveu a partir dos traços de uma constante atenção da sociedade para os objetos de uso (McCARTHY, 2002).

A linguagem mercantilista dentro da sociedade possuía traços muito fortes, conforme descreve o autor Umberto Eco (2004):

A redução de todo o objeto a mercadoria e o progressivo desaparecimento do valor de uso em um mundo regulado unicamente pelo valor de troca modifica radicalmente a natureza dos objetos cotidianos: o objeto deve ser útil, prático, relativamente econômico, de gosto comum, produzido em série. Isso significa que no circuito das mercadorias os aspectos qualitativos da Beleza transferem-se cada vez mais para os aspectos quantitativos. (Pg. 376)

Os objetos e a linguagem cotidiana, neste movimento, são elevados ao patamar de obras de arte e expostos em museus. O termo "pop", originário da língua inglesa, é uma derivação do termo "popular", que inicialmente significava o produzido em massa e acessível. No decorrer do tempo, ele se consolidou como um movimento que resgatava a consciência e o conteúdo da arte em si, que fora esquecida pela sociedade comum (McCARTHY, 2002).

Na percepção do autor Umberto Eco (2004), os artistas desse movimento possuíam algumas características na concepção de suas obras de arte:

Com olhar lúcido e frio, unidos muitas vezes a um declarado cinismo, os "popular artists" tomam consciência da perda por parte do artista do monopólio das imagens, da criação estética e da Beleza. (Pg. 377)

Os artistas vinculados a esse movimento pregam em suas obras a defesa de uma arte popular (pop) que se comunique diretamente com o público por meio de signos e símbolos retirados da própria cultura de massa e a vida cotidiana. Assim, a Pop Art se colocou na cena artística como um dos movimentos que recusam a separação arte/vida. Os artefatos concebidos por estes artistas possuem traços 
característicos, pois são originários das histórias em quadrinhos, da publicidade, das imagens televisivas e do cinema (McCARTHY, 2002).

Um exemplo que podemos usar para apresentar a lógica deste movimento é a colagem de Richard Hamilton, conforme a figura 1 abaixo, concebida inicialmente como um pôster e uma ilustração do catálogo para a exposição This is Tomorrow? Do Independent Group de 1956, na Whitechapel Art Gallery em Londres.

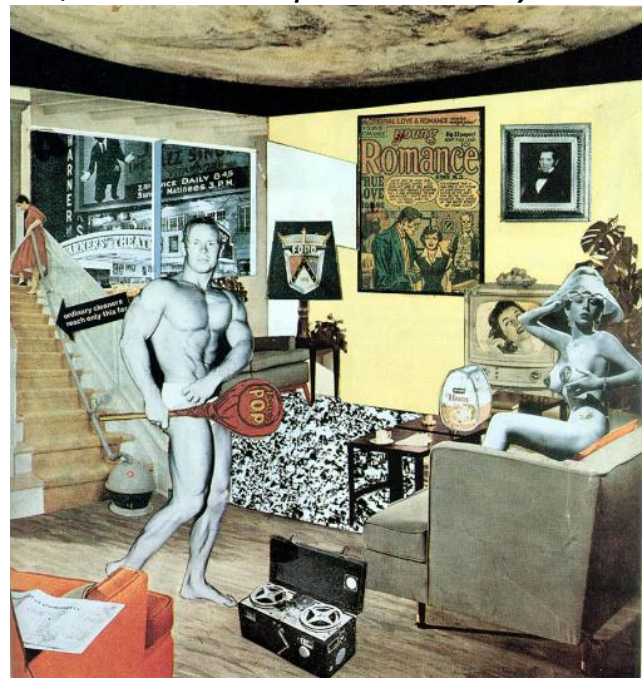

Figura 1 - Colagem intitulada “O que exatamente torna os lares de hoje tão atraentes?” Fonte: makingarthappen.com

As imagens recortadas e rearranjadas nesta obra de arte são um questionamento do artista para a sociedade. É a demonstração de um lar cheio de produtos projetados para o consumo reunidos em torno de um casal "também projetado" - porque ambos possuem um padrão quase inatingível de perfeição representando o culto ao belo como mercadoria.

De acordo com McCarthy (2002):

Os anúncios são descolados de seus contextos e transpostos para a obra de arte, guardam a memória de seu lócus original. Ao aproximar arte e design comercial, o artista borra, propositadamente, as fronteiras entre arte erudita e arte popular, ou entre arte elevada e cultura de massa.

Durante os seis anos seguintes a criação desta colagem de Richard Hamilton, a Pop Art, se configurou como uma força decisiva na arte ocidental inglesa e americana. Nos Estados Unidos, esse movimento apontou seus principais ícones, como Andy Warhol, Roy Lichtenstein, Claes Oldenburg, James Rosenquist e Tom Wesselmann. Esses artistas apresentavam semelhanças em sua linguagem artística, principalmente com o uso de cores brilhantes e contrastantes, desenho simplificado e tema comum. A Pop Art estava também vinculada a momentos de mudança política e serviu como uma espécie de espelho para a sociedade se enxergar e se questionar sobre os padrões estéticos impostos pela indústria cultural através de uma "caricatura de si mesmo", proposta pelas obras de arte que possuíam uma linguagem retirada do próprio dia a dia.

Dessa forma, esse movimento trouxe vários talentos que afetaram diretamente o curso da arte que veio posteriormente em todo o mundo e reconfigurou o que entendemos como cultura. Segundo McCarthy (2002): 
A arte pop evitou a rigidez e/ou as censuras em favor de uma arte visual e verbal, figurativa e abstrata, criada e apropriada, artesanal e produzida em massa, irônica e sincera. Era tão complexa e dinâmica quanto o momento e os artistas que lhe deram vida.

Outro movimento artístico, destacado neste artigo, que exacerbou os conceitos da contracultura e da Pop Art, além de criar outra linguagem rica em significação para os objetos e valores da sociedade, foi a Art Kitsch.

\subsection{Art Kitsch}

Este movimento controverso, não possui uma única definição. Moles (1994) afirma que Kitsch é um conceito que corresponde a um estilo institucionalizado pela ausência de estilo, uma elevação do supérfluo a obra de arte.

Na sociedade padronizada pela indústria cultural, o gosto é articulado para aumentar o consumo (ADORNO, 1985) e qualquer desvio deste padrão imposto pode ser considerado de "mau gosto". O mau gosto é reconhecido como algo "fora do lugar", algo que é menos adequado ao contexto em que está inserido. Relacionada a uma trapaça, como vender uma coisa no lugar de outra (ECO, 1998).

A Kitsch Art articula um rompimento do sistema criando novos parâmetros culturais, seu objetivo não é criar novas expectativas, mas sim, satisfazer as expectativas já existentes, podendo tornar-se, mais do que uma preferência estética, uma forma de vida (KULKA, 1996). Para Abraham Moles (1994), o kitsch é "a arte da felicidade".

Nas obras desse movimento, há o deslocamento de um elemento em particular que é transferido de sua autêntica categoria e adaptada a um fim diferente daquele ao qual estava destinado, esse lugar de destino pode ser uma obra de arte, uma camiseta, um objeto de decoração, um anúncio ou até uma identidade visual de uma empresa. Esse elemento é utilizado com intenções distintas daquelas originalmente concebidas. Há o que se chama um desvio da norma. O signo é descontextualizado como meio de aumentar a eficiência da mensagem (DORFLES, 1973).

Podemos utilizar como exemplo, a escultura do artista Jeff Koon, intitulada Michael Jackson and Bubbles, da série Banality, de 1998, conforme podemos ver na figura 2 abaixo.

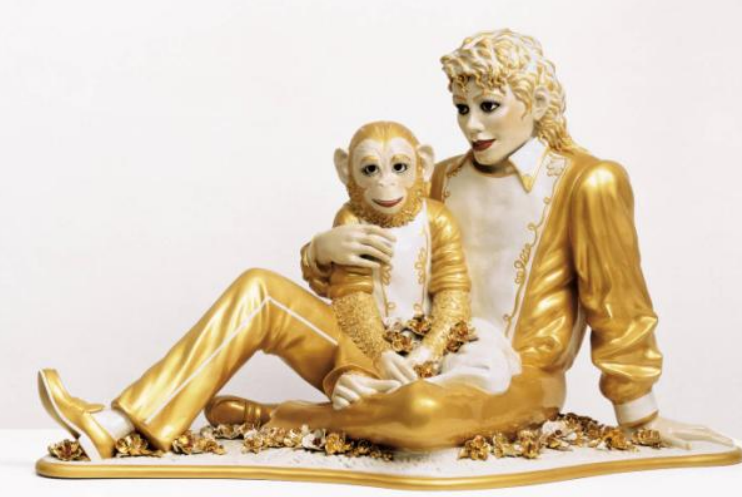

Figura 2 - Escultura intitulada "Michael Jackson and Bubbles"

Fonte: arthistory.com 
Nesta obra de arte podemos perceber claramente o deslocamento dos elementos de contextos divergentes que se fundem para transmitir uma mensagem irônica, divertida e contestadora. O desvio da norma, neste caso, é a convergência de linguagens distantes, através da apropriação da figura de um artista pop (Michael Jackson) que migra para a linguagem dos objetos ornamentados em excesso (Ovos Fabergé). O resultado dessa "mistura", promovida por essa escultura, vai além, porque podemos perceber também alguns questionamentos para a sociedade, como o racismo, o sexismo e a grande valorização do consumo.

Por isso, podemos dizer que no sistema da arte está a ética e no sistema do kitsch, o verniz da ética: a estética. A ética dá à obra o caráter transcendental, celeste e, portanto, dialético; no kitsch, está a realidade terrena, que repousa na exaltação. Tenta unir céu e terra em uma relação absolutamente falsa. Enquanto as obras de arte transcendem ao homem, ao seu autor, o kitsch confunde as categorias estéticas com as éticas e obedece a imperativos morais falsos (MOLES, 1994).

\section{CONCLUSÃO}

Como visto, a indústria cultural levou à padronização e à produção em série, abandonando a lógica da obra e massificando o sistema social. A sociedade se tornou reduzida a um simples material estatístico para a produção de produtos e para a elevação do consumo (ADORNO, 1985). Essa manipulação social, por parte da indústria cultural, transformou e dominou o gosto das pessoas. Elas foram condicionadas a perceber, em função disso, que a beleza significa e serve como acessório. A dominação articulada impôs padrões estéticos que visavam à exposição das divisões das classes sociais, desconstruindo a sociedade e alargando ainda mais seu domínio.

Para contrapor essa imposição estética, algumas pessoas buscaram na própria arte, uma forma de contestação, para criar uma ruptura dos hábitos consagrados de pensamentos e comportamentos da cultura dominante, no movimento artístico chamado de Contracultura (GOFFMAN, 2007). Mas os princípios da Contracultura se alargaram, disseminaram e fomentaram novas linguagens artísticas que também marcaram a história. Neste artigo, sublinhamos dois movimentos muito influentes para arte e o design: a Pop Art e a Art Kitsch.

Assim, estes dois movimentos ricos e polêmicos, se utilizaram de elementos da própria cultura de massificação e dos padrões estéticos impostos, para contrapor essa pressão recebida. A lógica dessas manifestações artísticas é o deslocamento dos contextos e a manipulação dos signos, unidos em outro contexto dessemelhante, para criar um estranhamento e um questionamento social.

Podemos concluir que ambos os movimentos articularam a significação da arte, trazendo para a superfície da realidade da massa consumidora, um "produto" no qual a própria sociedade se reconhece e também se estranha. Embora os fatos abordados nesse artigo sejam do século passado, essa discussão é totalmente atual e pertinente, pois a banalidade e a alienação estão 24 horas por dia em todos os meios de comunicação.

A qualidade da informação que é colocada a disposição do público não permite que haja uma reflexão mais sofisticada e, portanto a sociedade não soube aproveitar o verdadeiro potencial desses grandes movimentos culturais. 


\section{REFERÊNCIAS}

ADORNO T; HORKHEIMER M. Dialética do esclarecimento. Rio de Janeiro: Jorge Zahar Editor, 1985.

BOURDIEU, P. O poder simbólico. Rio de Janeiro: Bertrand Brasil, 1998.

BOURDIEU, P; PASSERON, J. C. Meditações pascalianas. Rio de Janeiro: Bertrand Brasil, 2001.

CANEVACCI, M. Culturas extremas. Rio de Janeiro: DP\&A, 2005.

COSTA, C. Questões de arte - o belo, a percepção e o fazer artístico. São Paulo: Moderna, 2004.

DORFLES, G. El kitsch. Barcelona: Editorial Lumen, 1973.

ECO, U. Apocalípticos e integrados. São Paulo: Perspectiva, 1998.

ECO, U. História da beleza. Rio de Janeiro: Record, 2004.

GOFFMAN K; JOY D. Contracultura através dos tempos. Rio de Janeiro: Ediouro e Sinergia, 2007

KULKA, T. Kitsch and art. Pennsylvania State University Press, 1996.

MARCUSE, H. Eros e civilização. Rio de Janeiro: LTC Editora, 1999.

McCARTHY, D. Arte pop. São Paulo: Cosacnaify, 2002.

MOLES, A. O kitsch. São Paulo: Editora Perspectiva, 1994. 